\title{
Mutation screening in Rett syndrome patients
}

Fengqing Xiang, Silvia Buervenich, Piero Nicolao, Mark E S Bailey, Zhiping Zhang, Maria Anvret

Department of Clinical Neuroscience,

Karolinska Hospital, Stockholm, Sweden F Xiang ${ }^{\star}$

P Nicolao

Z Zhang

M Anvret*

\section{Department of}

Molecular Medicine,

Karolinska Hospital,

Stockholm, Sweden

F Xiang

S Buervenich

P Nicolao

Z Zhang

M Anvret

\section{Department of}

Neuroscience,

Karolinska Institute,

Stockholm, Sweden

S Buervenich

Department of

Neurology and

Psychiatry (Second

Neurological Clinic),

University of Padova,

Italy

P Nicolao

Division of Molecular Genetics, Institute of Biomedical and Life

Sciences, University of Glasgow, Glasgow, UK M E S Bailey

Correspondence to: Dr Xiang, Department of

Molecular Medicine, Clinical

Neurogenetic Unit

CMM-L8-02, Karolinska

Hospital, 17176 Stockholm,

Sweden.

Fengqing.Xiang@cmm.ki.se

^Present address:

AstraZeneca R\&D

Södertälje, 15158 Södertälje,

Sweden

Revised version received 3 January 2000

Accepted for publication

26 January 2000

\begin{abstract}
Rett syndrome (RTT) was first described in 1966. Its biological and genetic foundations were not clear until recently when Amir et al reported that mutations in the $M E C P 2$ gene were detected in around 50\% of RTT patients. In this study, we have screened the $M E C P 2$ gene for mutations in our RTT material, including nine familial cases (19 Rett girls) and 59 sporadic cases. A total of 27 sporadic RTT patients were found to have mutations in the $M E C P 2$ gene, but no mutations were identified in our RTT families. In order to address the possibility of further $X$ chromosomal or autosomal genetic factors in RTT, we evaluated six candidate genes for RTT selected on clinical, pathological, and genetic grounds: UBE1 (human ubiquitin activating enzyme $\mathrm{E} 1$, located in chromosome Xp11.23), UBE2I (ubiquitin conjugating enzyme E2I, homologous to yeast UBC9, chromosome 16p13.3), GdX (ubiquitin-like protein, chromosome Xq28), SOX3 (SRY related HMG box gene 3, chromosome Xq26-q27), GABRA3 ( $\gamma-$ aminobutyric acid type $A$ receptor $\alpha 3$ subunit, chromosome Xq28), and CDR2 (cerebellar degeneration related autoantigen 2, chromosome 16p12-p13.1). No mutations were detected in the coding regions of these six genes in $\mathbf{1 0}$ affected subjects and, therefore, alterations in the amino acid sequences of the encoded proteins can be excluded as having a causative role in RTT. Furthermore, gene expression of $M E C P 2, G d X, G A B R A 3$, and L1CAM (L1 cell adhesion molecule) was also investigated by in situ hybridisation. No gross differences were observed in neurones of several brain regions between normal controls and Rett patients.

(F Med Genet 2000;37:250-255)
\end{abstract}

Keywords: Rett syndrome; mutation screening; in situ hybridisation; candidate gene

Rett syndrome (RTT) is a childhood neurodevelopmental disorder that almost exclusively affects females, with a prevalence of approximately 1 in $10000-15000 .{ }^{1}$ It had been suggested to be a genetic disorder because of the existence of a small number of familial cases, and because it shows a higher degree of concordance in monozygotic (MZ) than dizygotic (DZ) twins. ${ }^{2}$ Rett syndrome is characterised by stereotypical hand movements, loss of acquired skills, breathing dysfunction, gait abnormalities, autistic behaviour, and mental retardation. Besides the "classical RTT" described by Hagberg et $a l^{3}$ and Diagnostic
Criteria Working Group, ${ }^{4}$ there also exist nonclassical RTT or Rett variants, known as "forme fruste RTT". The fact that only females are affected and most cases are sporadic suggested that RTT could be an X linked dominant disease with lethality in affected males. Alternatively, Thomas ${ }^{6}$ hypothesised that a locus on the $\mathrm{X}$ chromosome that was prone to a higher rate of mutation during spermatogenesis than during oogenesis could explain these features. Our finding of linkage of RTT to the telomeric region of $\mathrm{Xq}^{7}$ is consistent with this model and has recently been validated by other groups. ${ }^{89}$

Recently, mutations in the $\mathrm{X}$ linked MECP2 gene were identified in some RTT patients by Amir et al. ${ }^{10}$ Methyl-CpG-binding protein 2 (MeCP2) is an abundant chromosomal protein that binds specifically to methylated $\mathrm{CpG}$ dinucleotides. The protein consists of a methylCpG binding domain (MBD), ${ }^{11}$ a transcriptional repression domain (TRD), ${ }^{12}$ and a corepressor interacting region. ${ }^{13} \mathrm{MeCP} 2$ protein selectively binds to methylated $\mathrm{CpG}$ dinucleotides in the genome and mediates transcription repression through interaction with histion deacetylase and the corepressor SIN3A.

Because MECP2 mutations have not been shown in all affected subjects, there is still the possibility of other genetic factors involved in the pathogenesis of RTT, as earlier suggested by Bühler et al, ${ }^{14}$ including the $\mathrm{X}$ chromosome and autosomal loci.

We have therefore confirmed the frequent presence of MECP2 mutations in our own RTT material and adopted a candidate gene approach for further exclusion of genes involved in RTT. One group of candidates was chosen to examine the possibility that enzymes involved in ubiquitination of proteins might be involved in RTT. Previous studies have shown that mutations in the ubiquitin protein ligase E3A $(U B E 3 A)$ gene cause Angelman syndrome (AS), ${ }^{15} 16$ which is characterised by mental retardation, seizures, hypotonia, epilepsy, absence of speech, and abnormal gait; these phenotypic characteristics overlap those of RTT to a considerable extent. Consequently, we screened three genes involved in the ubiquitination pathways (UBE1, UBE2I, and $G d X)$. UBE1 catalyses the first step in ubiquitin conjugation. UBE2I is essential for cell viability. ${ }^{17} G d X$ is a housekeeping gene that encodes a protein similar to ubiquitin. ${ }^{18}$ Four further genes (SOX3, GABRA3, CDR2, and $L 1 C A M)$ were selected based on their expression patterns or their known roles in neural function. Among all these, three, $G d X$, $G A B R A 3$, and $L 1 C A M$, are located in Xq28. We have also found evidence for regions on several autosomes that are concordant in 
affected patients from several familial Rett cases (unpublished data). Two of the genes examined here, UBE2I and $C D R 2$, are located in one of these candidate regions, chromosome $16 \mathrm{p} 12-\mathrm{p} 13$.

SOX3 is closely related to SRY, the mammalian sex determining gene on the $Y$ chromosome. ${ }^{19}$ The mouse homologue of SOX3 is expressed at high levels in neuronal tissues during development. The possibility of compensatory expression of the $S R Y$ gene in males in the presence of a mutated SOX 3 allele on the $\mathrm{X}$ chromosome could account for the lack of the RTT phenotype in males and could lead to disease presentation in females only.

$G A B R A 3$ is expressed during development of the brain. It also constitutes a good a priori candidate for the site of the biological lesion in Rett syndrome. It is one of the most widely expressed $\mathrm{GABA}_{\mathrm{A}}$ receptor subunits during mammalian fetal brain development. However, based on studies in rodents, it is rapidly downregulated during the first few weeks after birth $^{2021}$ throughout most of its realm of expression, while in a few areas it is present at higher levels in the adult than in the perinatal brain. There is a considerable degree of congruence between the expression domains of $G A B R A 3$ in the late mammalian embryo and the sites of neuronal pathology in Rett syndrome, including deeper cortical layers and brain stem areas involved in the sleep and breathing dysfunction seen in RTT patients. $^{20-25}$

No function has been postulated for $C D R 2$, but it is expressed in the nervous system and in neoplasms of ovary, breast, and endometrium. These tissues are oestrogen sensitive, and we have explored the interesting possibility that this pattern of expression might reflect a role for $C D R 2$ in regulation of sex specific differentiation in the nervous system, another mechanism that might underlie a sex limited disorder.
Additionally, gene expressions of $G d X$, GABRA3, L1CAM, and MECP2 were investigated by in situ hybridisation using postmortem brain tissue. The $\mathrm{L} 1$ adhesion molecule is expressed mainly on neural cells and is involved in neurone-neurone adhesion and has an important function in the development of the nervous system. Mutations in L1CAM have already been shown to lead to X linked mental retardation syndromes, including $\mathrm{X}$ linked hydrocephalus (HSAS), MASA syndrome (Mental retardation, Aphasia, Shuffling gait, and Adducted thumbs), X linked complicated spastic paraparesis (SP1), and X linked corpus callosum agenesis (ACC). ${ }^{26}$

\section{Materials and methods}

Ten unrelated patients with "classical" Rett syndrome and normal controls were used in the mutation screening for six candidate genes. For mutation screening of the MECP2 gene, 59 sporadic cases and nine familial RTT cases were included. Genomic DNA was extracted from blood samples using standard methods. Total RNA was isolated from lymphoblastoid cell lines using the Ultraspec ${ }^{\mathrm{TM}}$-II RNA kit (Biotecx). First strand cDNA was synthesised using the First-Strand cDNA Synthesis Kit (Pharmacia Biotech). PCR amplification was carried out using standard protocols. The coding region of $S O X 3$ is GC rich; therefore, a higher temperature $\left(98^{\circ} \mathrm{C}\right)$ was used in the denaturing step during each PCR cycle. Primer pairs were designed from published sequences to amplify the entire coding regions of the seven candidate genes (table 1). Taq PCR Core Kit (Giagen) was used for MECP2-3-2 in order to increase PCR sensitivity. PCR products were isolated from low melting temperature agarose gels and purified using Wizard ${ }^{\mathrm{TM}}$ PCR Preps DNA Purification System (Promega). Mutation analysis was performed by direct sequencing (Thermo Sequenase radiolabelled terminator cycle sequencing Kit,

Table 1 Primer pairs used in PCR amplification of the seven candidate gene coding regions

\begin{tabular}{|c|c|c|c|}
\hline Primer pairs & Forward primer (5'-3') & Reverse primer (5'-3') & $\begin{array}{l}\text { Annealing } \\
\text { temp }\left({ }^{\circ} \mathrm{C}\right)\end{array}$ \\
\hline UBE1-1 & CAGTCCGTGTTGTCCGA & GCCCGGTTTTTACCGATG & 55 \\
\hline UBE1-2 & AGGAGGACATCGGTAAAAC & ACTTGGCGAAGTCCGTCA & 55 \\
\hline UBE1-3 & GACTTTGTGGTGACGGAC & GTGTCCATGTCTGTAACGA & 55 \\
\hline UBE1-4 & AGGGTGGAGAAATCATCG & CTGCCGGATGTTGTTCGA & 55 \\
\hline UBE1-5 & CACCCAGTACTCGAACAA & GCTCTGTCTTAAAATAGTCG & 55 \\
\hline UBE1-6 & TCAAACAGTTCCTCGACTATT & GCGGATGGTGTATCGGAC & 55 \\
\hline UBE2I & TCCACCTGTCCGCTACGCT & CAATCССТTCCTTCTGACGAT & 59 \\
\hline GdX1-1 & ACTTGGCCCGACTGGTTCCT & CCGCACCCCGACCCGACACA & 62 \\
\hline GdX1-2 & AGTGGACGCCGTCGCGAC & ACACACGGCTGCTGGCCTC & 60 \\
\hline $\mathrm{GdX} 2$ & AGGAGGAACCCATCGATCT & AACACACTTAGTGCGACATGC & 57 \\
\hline SOX $3-1$ & AGCTAGAGCCCAGGCAGACT & СTTTCTTGAGCAGCGTCTTG & 59 \\
\hline SOX3-2 & CCGGACTACAAGTACCGACC & GCTGAGAGTGCGATGCGATG & 59 \\
\hline SOX $3-3$ & CCATGGGCTCGGTAGTGAAGT & GTGGGGAACAAGGGTGGAC & 59 \\
\hline GABRA3-1-1 & CATCCTTCTCTCCTTTCCGCT & GTGTCCGGTGTCCAGATCTT & 55 \\
\hline GABRA3-1-2 & CTCAGACTGTAGAGCTCGGT & GATTGTTCAGTGGAAGGATC & 58 \\
\hline GABRA3-2-1 & AGTGAAGACTGACATCTACGTG & GGCACTGATACTCAAGGTG & 55 \\
\hline GABRA3-2-2 & CAGACATGGCATGATGAAAGA & TGTACGGGCAGGAACAGAC & 57 \\
\hline GABRA3-3 & TGGCTACTTTGTGATCCAGA & GATGCTTCACGGGGTATAC & 57 \\
\hline CDR2-1 & GCCGAGATGCTGGCGGAAA & GATGACTTCAGCTCCTCCACT & 62 \\
\hline CDR2-2 & AGATTCTGAGCCTGACTGAAA & AACATACAGAGAGTCTGGCAC & 59 \\
\hline CDR2-3 & AGGCCGAGGTCGCAGAGATG & AGAGAGGCGATAGGCAATAGG & 62 \\
\hline MECP2-1 & ACACACACTGACCTTTCAGG & AATGTCCCAAATAGCCCTGG & 60 \\
\hline MECP2-2 & CCTGGGCACATACATTTTCCT & TGGCATGTTCTCTGTGATACTT & 60 \\
\hline MECP2-3-1 & CCCACCCTGAAGCCACGAAACT & СCTGCССССАССТССАССТG & 67 \\
\hline MECP2-3-2 & CTGCTGCTCAAGTCCTGGGGCT & CGACCCTCAGGCCATTCCCAAGA & 68 \\
\hline MECP2-3-3 & TCCTTCACGGCTTTCTTTTTGG & TCCTTGTGTCTTTCTGTTTGTC & 60 \\
\hline
\end{tabular}


Table 2 Oligonucleotide probes used for in situ hybridisation. Two different probes were used for GABRA3 and MECP2

\begin{tabular}{ll}
\hline Gene & Oligonucleotide sequences (5'-3') \\
\hline GdX & TAGGTTGAGCTTGGAGTTGGGCCCGATGCTATAATCCGAGAGTCGTTTCC \\
LICAM & TTTCAGCAGCTGCAGGGTCTTGTTGTGGTTCTGGTAGGTGACACGGTCGG \\
GABRA3 (1) & CATGGGGCCATCAAATTCAGTCTTTCATCATGCCATGTCTGCCGAAAA \\
$M A B R A 3(2)$ & GGAGATGGTGGAAATTCAGTGTCCTTGGCCAGGTTGATGGGATAGGTG \\
$M E C P 2(2)$ & ACTTCCCAGCAGAGCGGCCAGATTCCTTTGCTTAAGCTTCCGTGTCA \\
& CAGGGCTCTTACAGGTCTTCAGTCCTTTCCCGCTCTTCTCACCGAGGGT \\
\hline
\end{tabular}

Amersham Life Science) followed by electrophoresis on $6 \%$ denaturing polyacrylamide gels and autoradiography or using Applied Biosystem (ABI) 377 Sequencer. For the six deletions and one insertion detected in this study, both methods were performed to confirm the mutations.

Postmortem brain tissue samples were partly obtained from the Harvard Brain Tissue Resource Center and partly provided by Dr D Armstrong, Baylor College of Medicine, USA. Fresh frozen material from the superior frontal cortex, motor cortex, thalamus, and brain stem of six Rett girls (aged 6 to 17 years) and from seven controls (both males and females, aged 2 to 94 years) was available. Unfixed, $14 \mu \mathrm{m}$ thick cryosections were made and stored at $-20^{\circ} \mathrm{C}$ until use. Sections were removed from the freezer and air dried five hours before hybridisation. In situ hybridisation was carried out as described elsewhere. ${ }^{28}$ Briefly, oligonucleotides (table 2) complementary to the four genes of interest and one random nucleotide of similar length (negative control) were 3' end labelled with ${ }^{35} \mathrm{~S}$-dATP (to ensure high sensitivity and accurate cellular localisation) using terminal transferase. Forty ng of labelled oligonucleotide per slide were added to $100 \mu \mathrm{l}$ of hybridi-

Table 3 Mutations of MeCP2 found in this study

\begin{tabular}{|c|c|c|c|c|}
\hline Patients No & Mutation type & Region or domain & Nucleotide change* & $\begin{array}{l}\text { Amino acid } \\
\text { changet }\end{array}$ \\
\hline 30 & Deletion & Poly $\mathrm{H}+$ poly $\mathrm{P}$ & nt1233(del43) & Frameshift \\
\hline 57 & 一 & - & nt1172(del70) & - \\
\hline - & - & & nt1256(del7) & - \\
\hline 62 & - & Poly $\mathrm{H}+$ poly $\mathrm{P}$ & nt1170(del101) & - \\
\hline 72 & - & - & nt1194(del69) & \\
\hline 86 & - & - & nt 1215 (del55) & Frameshift \\
\hline - & Insertion & & nt1127(ins 10) & - \\
\hline $28 \rrbracket$ & Missense & TRD & $990 \mathrm{C} \rightarrow \mathrm{T}$ & R306C \\
\hline $29 \$$ & - & - & - & - \\
\hline 32 & - & - & - & - \\
\hline 64 & - & - & - & - \\
\hline 67 & - & - & - & - \\
\hline 78 & - & - & - & - \\
\hline 91 & - & - & - & - \\
\hline 39 & - & MBD & $390 \mathrm{C} \rightarrow \mathrm{T}$ & R106W \\
\hline 70 & - & - & - & - \\
\hline 80 & - & - & $365 \mathrm{C} \rightarrow \mathrm{A}$ & D97E \\
\hline 41 & - & - & $471 \mathrm{C} \rightarrow \mathrm{T}$ & R133C \\
\hline 79 & - & - & $537 \mathrm{~T} \rightarrow \mathrm{A}$ & F155I \\
\hline 45 & - & - & $547 \mathrm{C} \rightarrow \mathrm{T}$ & T158M \\
\hline $18^{\star \star}$ & Nonsense & TRD & $837 \mathrm{C} \rightarrow \mathrm{T}$ & $\mathrm{R} 255 \mathrm{X}$ \\
\hline 42 & - & - & - & - \\
\hline 76 & - & - & - & - \\
\hline 43 & - & - & $954 \mathrm{C} \rightarrow \mathrm{T}$ & R294X \\
\hline 48 & - & - & - & - \\
\hline 55 & - & - & - & - \\
\hline 33 & - & CRIR+† & $576 \mathrm{C} \rightarrow \mathrm{T}$ & $\mathrm{R} 168 \mathrm{X}$ \\
\hline 44 & - & - & - & - \\
\hline 52 & - & - & - & - \\
\hline
\end{tabular}

^Nucleotide number according to GenBank accession No X99686.

†Amino acid number according to Genbank accession No CAA68001.

$\ddagger$ The same as above.

$§$ Patients 28 and 29 are a twin pair.

-Same mutation has been reported in ref 10 or ref 28

$\star \star$ Patient 18 is from a Rett "cluster" family.

t+Corepressor interacting region. sation cocktail containing $4 \times$ SSC, $50 \%$ formamide, $1 \times$ Denhardt's solution, $1 \%$ sarcosyl, $0.02 \mathrm{~mol} / 1$ phosphate buffer ( $\mathrm{pH} 7.0$ ), $10 \%$ dextran sulphate, $50 \mathrm{mg}$ sheared salmon sperm DNA, and $200 \mathrm{mmol} / 1$ dithiothreitol. Slides were incubated overnight at $42^{\circ} \mathrm{C}$ in a humidified chamber. Subsequently, the slides were rinsed five times for 45 minutes at $60^{\circ} \mathrm{C}$ in $1 \times$ SSC, dehydrated through graded ethanol, air dried, dipped in photographic emulsion (Kodak NTB2 at 1:2 dilution), and exposed in the dark for six weeks. After developing, the slides were counterstained with cresyl violet and mounted.

\section{Results}

Mutations in the coding region of $M E C P 2$ were found in $35 \%$ of our cases. The MECP2 gene consists of three exons. The whole coding regions including the exon-intron junction were amplified by PCR $(\sim 1.5 \mathrm{~kb}$, Genbank accession Nos AF030876 and X99686). Primer information is shown in table 1. Altogether, we identified six deletions (from 7 bp up to $101 \mathrm{bp}$ ), one insertion (10 bp), six missense mutations, and three nonsense mutations (table 3 ) in 27 of 78 patients. Five of the six deletions and the insertion cause frameshifts, and the same mutations were not found in their parents or normal sibs. R106W, D97E, R133C, F157I, and T158M are located in MBD, R306C, R255X, and R294X are located in TRD, and R168X is in the corepressor interacting region. One patient has a $7 \mathrm{bp}$ deletion at nt 1256 and a $70 \mathrm{bp}$ deletion at $\mathrm{nt}$ 1172. Another patient has a $10 \mathrm{bp}$ insertion at nt 1127 and a 55 bp deletion at nt 1215. All the deletions and the insertion detected in our patients are clustered in a $150 \mathrm{bp}$ region (nt 1127-1275) which contains tandem repeats. This indicated that the region could be a hot spot for deletion owing to DNA polymerase slippage.

The UBE1 gene transcript (GenBank accession No M58028) is $3.5 \mathrm{~kb}$ in length and we used six pairs of primers to amplify the whole coding sequence $(3.2 \mathrm{~kb})$. In contrast, a single pair of primers was used to cover the entire coding region (spanning $476 \mathrm{bp}$ ) of UBE2I (GenBank accession No U45328). The gene structure of $G d X$ is known (Genbank accession No J03589) and primers were therefore designed using intronic sequence to amplify two PCR fragments, each containing two complete exons and the intervening intron. In order to increase the PCR specificity and sensitivity for $G d X$, a two round, nested PCR was used (GDX1-2 in table 1), and in addition, the Taq PCR Core kit was used. No mutations were 


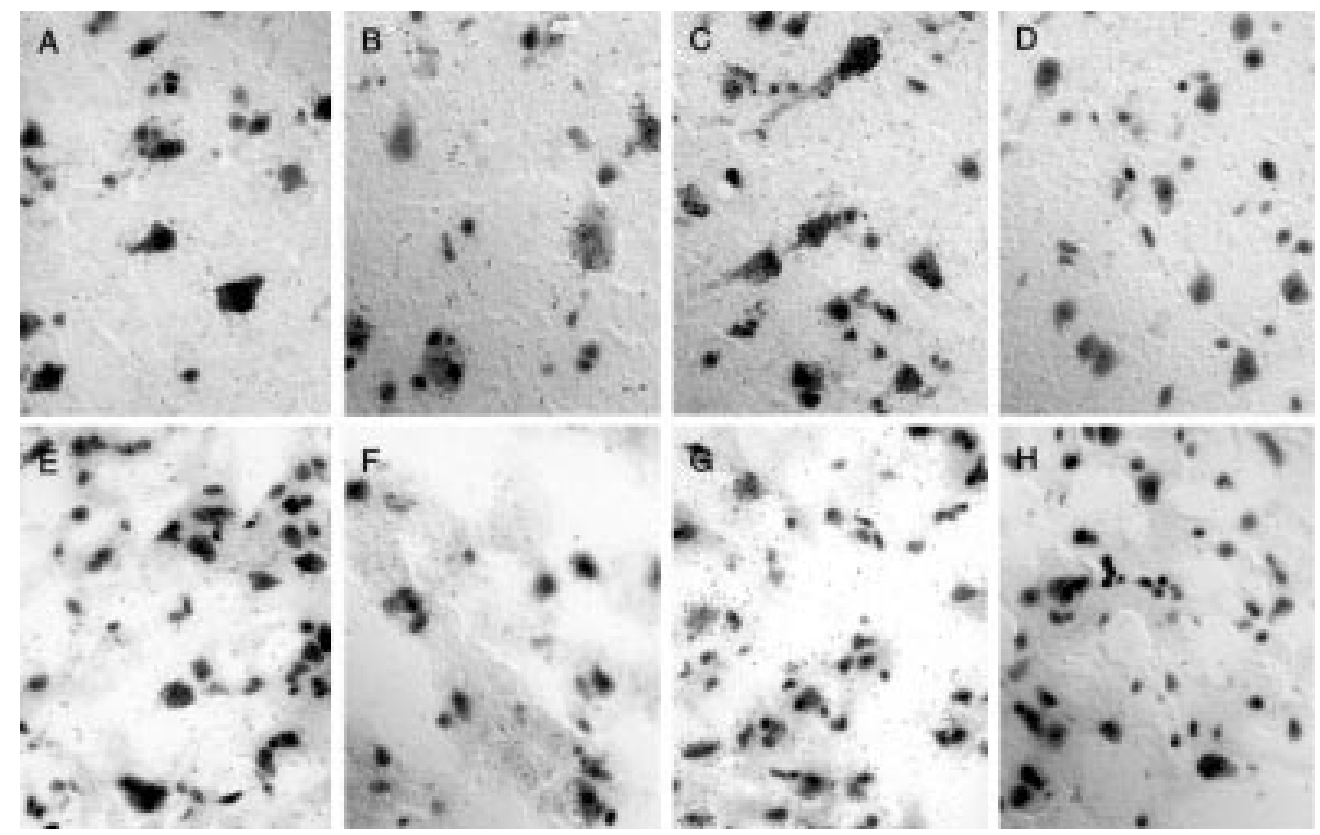

Figure 1 Bright field microscopy of neurones in the frontal cortex showing GABRA3 and L1CAM expression. Panels show representative fields from sections from a normal control $(A-D)$ and a Rett patient $(E-H)$. The first $(A, E)$ and the second $(B, F)$ probe for $G A B R A 3$ showed similarly low levels of expression. Relatively strong expression levels were detected with the probe against L1CAM. (C, G) Hybridisation with a random oligonucleotide resulted in low background signal $(D, H)$. No differences could be observed between patients and controls for any of the probes used.

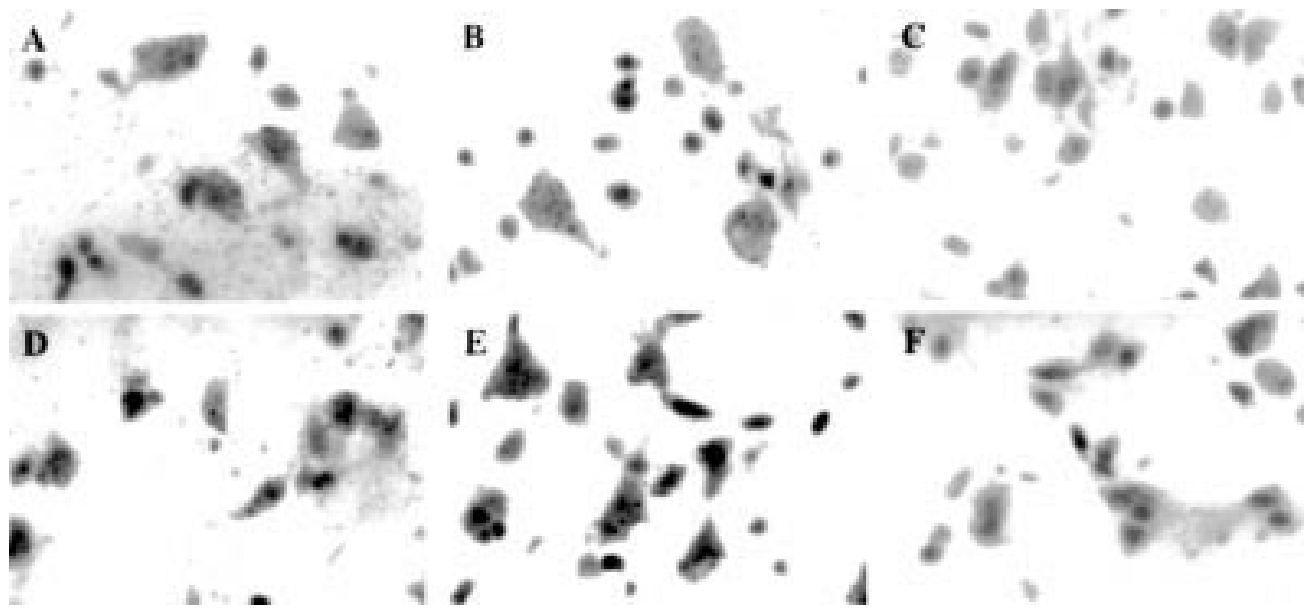

Figure 2 Bright field microscopy of neurones in the frontal cortex showing MECP2 and L1CAM expression. Panels show representative fields from sections from a normal control $(A-C)$ and a Rett patient $(D-F) . M E C P 2(A, D)$ was expressed at similar levels as L1CAM $(B, E)$. The negative control hybridisation $(C, F)$ displays very low background signal.

$M E C P 2$ was expressed ubiquitously in patients and controls in all brain tissues tested (besides the prefrontal cortex shown in this figure we also investigated expression in the motor cortex, thalamus, and brain stem, data not shown). No differences in expression between different brain regions or patients versus controls could be detected.

detected in the coding regions of $U B E 1$, $U B E 2 I$, or $G d X$.

SOX3 comprises a single exon. Three pairs of primers were used to amplify and sequence the 1331 bp region containing the coding sequence. An $8 \mathrm{bp}$ insertion (TGCCGCCG) in the gene was identified (between bases 1327 and 1328 of the sequence contained in the Genbank entry with accession number $\mathrm{X} 71135$ ). However, the insertion was present in all 12 subjects tested (10 patients and two normal controls) and the deletion variant may therefore represent an error in the original database sequence.

The coding region of $G A B R A 3$ spans $\sim 1.4$ $\mathrm{kb}$ (Genbank accession No A28102) and three primer pairs were used to amplify the coding region. The two most 5' fragments were ampli- fied using a two round, nested PCR strategy to increase PCR specificity and sensitivity. Three pairs of primers were designed to amplify the entire cDNA sequence of CDR2 $(\sim 1.3 \mathrm{~kb}$, Genbank accession No M63256). No mutations were found in either gene.

From the in situ hybridisation experiments, representative photomicrographs are shown in figs 1 and 2. L1CAM mRNA was detected at relatively high levels in neurones and lower levels in glia in all brain regions investigated (prefrontal cortex shown in figs 1 and 2, motor cortex, thalamus, and brain stem). A strong ubiquitous signal was generated by $M E C P 2$ specific oligonucleotides (fig 2). Low levels of $G A B R A 3$ and $G d X$ expression were found in sections containing tissue from these regions (fig 1). There were no detectable differences in 
expression levels or patterns for any of these four genes between Rett patients and controls.

\section{Discussion}

Recent evidence from genetic mapping using familial Rett cases has strongly indicated the presence of a gene for RTT in Xq28, finally leading to the discovery of mutations in $M E C P 2$. Because not all patients investigated so far carry mutations in $M E C P 2$ and because of the clinical variability seen in RTT, it is possible that this disorder may be genetically heterogeneous. In this study, we therefore determined the percentage of our Rett patients with MECP2 mutations to be $35 \%$ and screened further X chromosomal and autosomal candidate genes on the basis of their genomic locations or physiological or genetic characteristics. For some of the candidate genes investigated here, we chose to sequence cDNA products, because full gene structures and sequences were not available for all the genes. In this way, we expected to be able to find mutations in the coding sequence that would be predicted to alter the amino acid sequence of the proteins. This strategy cannot identify mutations in the promoter or $5^{\prime}$ or $3^{\prime}$ untranslated regions. In addition, truncating mutations that reduce RNA stability might not be apparent. We can be sure that the latter problem was not encountered for most of the genes investigated here, because we were able to show the presence of heterozygous polymorphisms in several subjects (not shown), suggesting that effective biallelic amplification was occurring. It would clearly be desirable to extend these studies to include the remaining parts of these genes, to investigate whether other common types of mutation in these regions play a role.

By screening the $M E C P 2$ gene, 16 mutations were identified including missense mutations, nonsense mutations, an insertion, and deletions. Most of the point mutations are $\mathrm{C} \rightarrow \mathrm{T}$ transitions, which are located in the MBD or TRD or corepressor interacting region. The six deletions and one insertion are exclusively clustered within a $150 \mathrm{bp}$ region of exon 3 . Surprisingly, we detected two de novo deletions in the "hot spot" region in one patient and one deletion and one small insertion in the same region in another patient. Since it is extremely rare that two de novo mutations happen to occur in a small region and occur twice (two patients), the region is likely to be a hotspot for deletion or insertion. This region contains several tandem repeats; therefore, the region could be unstable owing to DNA polymerase slippage.

The missense mutation R306C was found in seven out of 78 patients ( $9 \%)$. In order to rule out the possibility of a common polymorphism, we used HhaI restriction enzyme to test 47 ethnically matched normal controls. None of the 47 normal controls carried this polymorphic site (data not shown). After completely sequencing the entire coding region, mutations were detected in only $35 \%$ of patients. There are some mutations that may be missed if they are located in introns, the promoter region, or the 3' untranslated region or consist of huge deletions. However, we have not identified any mutation in our nine familial RTT cases. Our results indicated that there might be more than one gene for RTT. MECP2 may play a key role in the development of the disease. Other genes that may interact with $M E C P 2$ or in the same pathway may contribute to the subset of RTT patients remaining unexplained so far.

Skewed $\mathrm{X}$ chromosome inactivation has been found in some of our familial RTT cases (paper submitted). The XIST gene (X inactive specific transcript), located at the $\mathrm{X}$ inactivation centre, XIC, and expressed exclusively from the inactive $\mathrm{X}$ chromosome, is thought to be the major gene involved in initiating the process of $\mathrm{X}$ chromosome inactivation. Previous studies of two unrelated families with skewed $\mathrm{X}$ chromosome inactivation have shown a promoter mutation in the XIST in nine females, indicating that there may be an association between alterations in the regulation of XIST expression and $\mathrm{X}$ chromosome inactivation. We then used the patients with skewed X chromosome inactivation and some other RTT patients without MECP2 gene mutation to test if there is any mutation in the promoter region of XIST. We could not find any mutation in the promoter region of XIST in any of the 10 patients tested (data not shown).

We also used in situ hybridisation to investigate the expression levels of a set of candidate genes. We predicted that mutations in these genes that caused gross alterations in transcription rates or in mRNA stability or localisation would be detected by this technique. The ability to detect such changes might be of use in narrowing down the search for candidates on which to perform a mutation scan. In the case of $M E C P 2$, changes in regional or global expression levels may be important clues for an understanding of the pathogenetic mechanisms underlying the syndrome. We observed no gross alterations of expression levels in the four genes tested (GABRA3, GdX, L1CAM, and $M E C P 2$ ), but two of them, GABRA3 and $G d X$, were expressed at relatively low levels and subtle changes in expression pattern or levels in patients would therefore be difficult to detect. When using postmortem material, there is the added danger that global degrading processes acting on mRNA will have proceeded too far to be able to detect transcripts. In this study, we detected high levels of L1CAM and $M E C P 2$ transcripts, suggesting that this problem did not occur in our samples.

We thank all the patients and their families for their participation, all doctors who provided the sample materials, $\mathrm{Dr}$ Nessa Carey and Dr Mark G Darlison for helpful comments, Dr Laurent Villard for helping design primers for $M E C P 2$ exon 1 , and Mrs Ann-Christin Thelander for excellent technical assistance. This work is supported by the Axel and Margaret Axson Johnson Foundation, the Emil and Wera Cornell Foundation, the Ragnar Söderberg Foundation, the International Rett Syndrome Association, and Karolinska Institutet, NIMH and USPHS funds. Brain tissues were provided by the Harvard Brain Tissue Resource Center, which is supported in part by PHS grant number MH/NS 31862 .

1 Hagberg B. Rett syndrome: prevalence and impact on progressive severe mental retardation in girls. Acta Paediatr Scand 1985;74:405-8. 
2 Wahlström J. Practical and theoretical considerations concerning the genetics of the Rett syndrome. Brain Dev 1987;9:466-8.

3 Hagberg B, Witt-Engerström I. Rett syndrome: a suggested staging system for describing impairment profile with increasing age towards adolescence. Am $\mathcal{F}$ Med Genet 1986; 24(suppl 1):47-59.

4 The Rett Syndrome Diagnostic Working Group. Diagnostic criteria for Rett syndrome. Ann Neurol 1988;23:425-8.

5 Hagberg B, Anvret M, Wahlström J, eds. Rett syndrome clinical and biological aspects. London: Mac Keith Press, 1993.

6 Thomas GH. High male:female ratio of germ-line mutation: an alternative explanation for postulated gestational lethality in males in X-linked dominant disorders. $A m \mathcal{F}$ Hum Genet 1996;58:1364-8.

7 Xiang F, Zhang Z, Clarke A, et al. Chromosome mapping of Rett syndrome: a likely candidate region on the telomere of Xq. $\mathcal{F}$ Med Genet 1998;35:297-300.

8 Sirianni N, Naidu S, Pereira J, Pillotto RF, Hoffman EP. Rett syndrome: confirmation of X-linked dominant inherRett syndrome: confirmation of X-linked dominant inher-
itance, and localization of the gene to Xq28. Am f Hum itance, and localization

9 Genet 1998;63:1553-8. Woods CG. Linkage analysis in Rett syndrome families suggests that there may be a critical region at Xq28. $\mathcal{F ~ M e d ~}$ Genet 1998;35:997-1003.

10 Amir RE, Van den Veyver IB, Wan M, Tran CQ, Francke U, Zoghbi HY. Rett syndrome is caused by mutations in $\mathrm{X}$-linked $M E C P 2$, encoding methy-CpG-binding protein 1. Nat Genet 1999;23:185-8

11 Nan X, Meehan RR, Bird A. Dissection of the methyl-CpG binding domain from the chromosomal protein MeCP2. Nucleic Acids Res 1993:21:4886-92.

12 Nan X, Campoy FJ, Bird A. MeCP2 is a transcriptional repressor with abundant binding sites in genomic chromatin. Cell 1997;88:471-81.

13 Nan X, Ng HH, Johnson CA, et al. Transcriptional repression by the methl-CpG-binding protein MeCP2 repression by the methl-CpG-binding protein MeCP2 386-9.

14 Bühler EM, Malik NJ, Alkan M. Another model for the inheritance of Rett syndrome. Am F Med Genet 1990;36 126-31.

15 Kishino T, Lalande M, Wagstaff J. UBE3A/E6-AP mutations cause Angelman syndrome. Nat Genet 1997;15:70-3
16 Matsuura T, Sutcliffe JS, Fang P, et al. De novo truncating mutations in E6-AP ubiquitin-protein ligase gene (UBE3A) in Angelman syndrome. Nat Genet 1997;15:74-7.

17 Jentsch S. The ubiquitin-conjugation system. Annu Rev Genet 1992;26:179-207.

18 Toniolo D, Persico M, Alcalay M. A "housekeeping" gene on the $\mathrm{X}$ chromosome encodes a protein similar to ubiquitin. Proc Natl Acad Sci USA 1988;85:851-5.

19 Stevanovic M, Lovell-Badge R, Collignon J, Goodfellow PN. SOX3 is an X-linked gene related to SRY. Hum $\mathrm{Mol}$ Genet 1993;2:2013-18.

20 Laurie DJ, Wisden W, Seeburg PH. The distribution of thirteen $\mathrm{GABA}_{\mathrm{A}}$ receptor subunit mRNAs in the rat brain. III. Embryonic and postnatal development. I Neurosci 1992;12: 4151-72.

21 Araki T, Tohyama M. Region-specific expression of $\mathrm{GABA}_{\mathrm{A}}$ receptor $\alpha 3$ and $\alpha 4$ subunits mRNAs in the rat brain. Mol Brain Res 1992;12:293-314.

22 Naidu S. Rett syndrome: a disorder affecting early brain growth. Ann Neurol 1997;42:3-10.

23 Wisden W, Laurie DJ, Monyer H, Seeburg PH. The distribution of thirteen $\mathrm{GABA}_{\mathrm{A}}$ receptor subunit mRNAs in the rat brain. I. Telencephalon, diencephalon, mesencephalon. f Neurosci 1992;12:1040-62.

24 Laurie DJ, Seeburg PH, Wisden W. The distribution of thirteen $\mathrm{GABA}_{\mathrm{A}}$ receptor subunit mRNAs in the rat brain. II. Olfactory bulb and cerebellum. F Neurosci 1992;12:106376.

25 Chang CCA, Luntz-Leybman V, Evans JE, Rotter A, Frostholm A. Developmental changes in the expression of $\gamma$-aminobutyric $\mathrm{acid}_{\mathrm{A}} /$ benzodiazepine receptor subunit mRNAs in the murine inferior olivary complex. $f$ Comp Neurol 1995;356:615-28.

26 Van Camp G, Fransen E, Vits L, Raes G, Willems PJ. A locus-specific mutation database for the neural cell adhesion molecule L1CAM (Xq28). Hum Mutat 1996;8: 391.

27 Dagerlind Å, Friberg K, Bean AG, Hökfelt T. Sensitive mRNA detection using unfixed tissue: combined radioactive and non-radioactive in situ hybridization histochemistry. Histochemistry 1992;98:39-49.

28 Wan M, Lee SS, Zhang X, et al. Rett syndrome and beyond: recurrent spontaneous and familial MECP2 mutations at CpG hotspots. Am f Hum Genet 1999;65:1520-9. 